\title{
Clinical and Electroencephalographic Profile Of Children
}

\author{
Limbu N, Paudel BH, Thakur D
}

Department of Basic and Clinical Physiology

B.P. Koirala Institute of Health Sciences (BPKIHS)

Dharan, Nepal

\section{Corresponding Author}

Nirmala Limbu

Department of Basic and Clinical Physiology

B.P. Koirala Institute of Health Sciences (BPKIHS)

Dharan, Nepal

E-mail: nirulim@yahoo.com

\section{Citation}

Limbu N, Paudel BH, Thakur D. Clinical And Electroencephalographic Profile Of Children. Kathmandu Univ Med J 2013;42(2):110-116.

\section{ABSTRACT}

\section{Background}

Reports on pediatric electroencephalogram of Nepalese patients are rare.

\section{Objective}

We aimed to study the relationship between provisional clinical and electrophysiological diagnoses of pediatric patients with documentation of demographic profiles, and type and frequency of the disorders/diseases.

\section{Methods}

Electroencephalographic reports of 634 children from 2006 to 2009 were analyzed at neurophysiology laboratory, department of Basic and Clinical Physiology, B. P. Koirala Institute of Health Sciences, Dharan, Nepal, retrospectively. Chi-Square test was applied after detail descriptive statistics.

\section{Results}

Male and female were $72.2 \%(n=458 / 634)$ and $27.76 \%(n=176 / 634)$ respectively. Most frequent EEG abnormality was seizure disorder $(n=370,59.39 \%)$, then febrile seizure $(n=$ $94,15.08 \%$ ) and birth asphyxia with hypoxic-induced encephalopathy ( $n=68,10.91 \%)$. Electroencephalogram showed significant epileptiform discharges in seizure disorder $(\mathrm{p}=0.001, \mathrm{OR}=2.26,95 \% \mathrm{Cl}=1.61$ to 3.18$)$ and in cerebral palsy $(\mathrm{p}=0.049, \mathrm{OR}=6.88$, $95 \% \mathrm{Cl}=0.89$ to 145.95$)$, specifically in 6 to $12(\mathrm{p}=0.001, \mathrm{OR}=2.94,95 \% \mathrm{Cl}=1.43$ to $6.06)$ and one to five $(p=0.019)$ years, respectively. Electroencephalogram detected significantly less epileptiform discharges ( $p=0.001, O R=0.25,95 \% \mathrm{Cl}=0.15$ to 0.42 ) in febrile seizure specifically in 1 to 5 years $(p=0.003, O R=0.16,95 \% \mathrm{Cl}=0.04$ to 0.63 ).

\section{Conclusion}

Predominant Electroencephalographic abnormality was seizure disorder, followed by febrile seizure and birth asphyxia with hypoxic-induced encephalopathy respectively. Electroencephalographic abnormality was highly associated with seizure disorder and cerebral palsy but was not associated with febrile seizure.

\section{KEY WORDS}

Children, EEG, epileptiform discharges 


\section{INTRODUCTION}

The electroencephalogram (EEG) is the algebraic summation of electrical activity (excitatory and inhibitory postsynaptic potentials) of the brain as recorded from electrodes placed on the scalp. ${ }^{1}$ Since it is a convenient and relatively inexpensive way to demonstrate the physiological manifestations of abnormal cortical excitability that underlies epilepsy, EEG continues to play a central role in diagnosis and management of patients with seizure disorders in conjunction with the remarkable variety of other diagnostic techniques. ${ }^{2}$

B.P. Koirala Institute of Health Sciences (BPKIHS) is a referral centre located at eastern part of Nepal. Patients coming for EEG at BPKIHS, range from transient loss of consciousness to seizure disorder. In addition, infants and children diagnosed with birth asphyxia with hypoxicinduced encephalopathy, meningitis, encephalitis, cerebral palsy, febrile seizures and others are also referred for EEG.

In the context of Nepal, there is virtually nonexistent literature and published data on reports on Pediatric EEG. Thus, we have attempted to study the relationship between provisional clinical and electrophysiological diagnoses of the pediatric patients with documentation of the demographic profiles, and the frequency of the disorders/ diseases referred for EEG at BPKIHS. This study would provide the preliminary documented data of the clinicoelectrodiagnostic relationship of the Nepalese children, which will open the avenues and provide background for the future research.

\section{METHODS}

This descriptive retrospective study included all the children referred for EEG to the department of Basic and Clinical Physiology, BPKIHS, from the year 2006 to 2009. Most of them were referred from the Pediatric OPD of BPKIHS and some from outside BPKIHS. EEG reports of children from neonates to 12 years of age were enrolled in this study. An EEG database had been maintained of all the cases at EEG laboratory, which included demographic profiles, relevant clinical history and findings, provisional clinical diagnosis, and electrophysiological diagnosis.

All the reports recorded were analyzed by two trained consultants jointly and were tabulated. The patients were divided into three age groups (less than one, one to five and six to12 years) according to the broad physiological EEG pattern. ${ }^{3}$ The electroencephalographic findings of each case were divided into normal and abnormal. Epileptiform discharges in EEG were based on standard criteria. ${ }^{3}$

From the total 634 cases recruited, only 623 cases were enrolled and 11 cases were excluded from the study. Exclusion was done on the basis of EEG findings. EEG recording with equivocal findings or immature record or with inconclusive evidence or non-specific findings or disagreement between consultants was excluded. Detail descriptive statistics was done in Microsoft Office Excel. Chi Square test was applied for the relationship between the provisional clinical diagnoses and electrodiagnoses. The study was conducted after the approval of the Ethical Review Board of the institute.

\section{RESULTS}

In the duration of three years (2006 to 2009), the total number of pediatric EEG done was 634 .

Age: The most common age group of children referred for EEG were six to 12 years ( $n=252,39.75 \%)$, followed by age group of one to five years $(n=239,37.70 \%)$ and less than one year ( $n=143,22.55 \%)$ respectively. In all age groups male were more (Table 1 ).

Sex: From the total cases of 634, 458 (72.24\%) were males and 176 (27.76\%) were females. In males, the most common age group was between one to five years $(n=178$, $38.86 \%)$ followed by six to 12 years $(n=169,36.98 \%)$ and less than one year ( $n=111,24.29 \%$ ) respectively (Table 1 ).

Whereas, in females, the most common referral age group was between six to 12 years $(n=83,47.15 \%)$ followed by one to five years $(n=62,35.22 \%)$ and less than one year $(n=32,18.18 \%)$ respectively (Table 1 ).

Table 1. Age and sex distribution of the patients referred for EEG during the year 2006 to 2009 at BPKIHS.

\begin{tabular}{llll}
$\begin{array}{l}\text { Age group } \\
\text { (year) }\end{array}$ & $\begin{array}{l}\text { No. of patients } \\
(\mathbf{n = 6 3 4 )}\end{array}$ & \multicolumn{2}{c}{ Sex } \\
& $\begin{array}{l}\text { Male (n=458, } \\
\mathbf{7 2 . 2 3 \% )}\end{array}$ & $\begin{array}{l}\text { Female( } \mathrm{n}= \\
176,27.76 \%)\end{array}$ \\
\hline$<1$ & $143(22.55 \%)$ & $111(24.29 \%)$ & $32(18.18 \%)$ \\
\hline $1-5$ & $239(37.70 \%)$ & $178(38.86 \%)$ & $62(35.22 \%)$ \\
\hline $6-12$ & $252(39.75 \%)$ & $169(36.98 \%)$ & $83(47.15 \%)$ \\
\hline
\end{tabular}

Geographical belongings of patients coming to BPKIHS and referred for EEG

Most of the patients referred for EEG were from the Eastern part of Nepal. Most frequently, patients referred were from Sunsari district $(n=231,36.43 \%)$, followed by Morang $(n=88,13.88 \%)$ and Jhapa districts $(n=74,11.67 \%)$ respectively. The patients were as far as from more than $200 \mathrm{Km}$ and from remote hill districts to plains. There were sizable patients from Bihar, India (Table 2).

\section{Relative frequency of cases referred for EEG during 2006 to 2009 at BPKIHS}

From the 623 cases, $59.39 \%(n=370)$ was seizure disorder, $15.08 \%(n=94)$ was febrile seizure, $10.91 \%(n=68)$ was birth asphyxia with hypoxic-induced encephalopathy. Others were meningitis/encephalitis $6.26 \%(n=39)$, seizure disorder with co-morbidity $2.56 \%(n=16)$ and cerebral palsy $1.60 \%(n=10)$. According to the age group it was as follows: 
Table 2. Geographical belongings of patients coming for EEG at BPKIHS in the year 2006 to 2009.

\begin{tabular}{|c|c|}
\hline District & No. of patients, $n=634$ \\
\hline Sunsari & $231(36.43 \%)$ \\
\hline Morang & $88(13.88 \%)$ \\
\hline Jhapa & $74(11.67 \%)$ \\
\hline Dhankuta & $29(4.57 \%)$ \\
\hline Saptari & $42(6.62 \%)$ \\
\hline Udaypur & $22(3.47 \%)$ \\
\hline Dhanusha & $38(6.20 \%)$ \\
\hline Siraha & $26(4.24 \%)$ \\
\hline Ilam & $9(1.42 \%)$ \\
\hline Bhojpur & $8(1.26) \%$ \\
\hline Terathum & $11(1.73 \%)$ \\
\hline Panchthar & $9(1.42 \%)$ \\
\hline Mahotari & $10(1.63 \%)$ \\
\hline Sankhuwasabha & $3(0.47 \%)$ \\
\hline Janakpur & $8(1.26 \%)$ \\
\hline Sarlahi & $6(0.94 \%)$ \\
\hline Taplejung & $3(0.47 \%)$ \\
\hline Khotang & $1(0.16 \%)$ \\
\hline Okhaldhunga & $1(0.16 \%)$ \\
\hline Sindhuli & $1(0.16 \%)$ \\
\hline Lahaan & $1(0.16 \%)$ \\
\hline Bardibas & $1(0.16 \%)$ \\
\hline Bihar (India) & $22(3.47 \%)$ \\
\hline
\end{tabular}

( $n=11,4.64 \%)$, seizure disorder with co-morbidity ( $n=$ nine, $3.79 \%)$, and cerebral palsy $(n=5,2.10 \%)$ (Table 3$)$.

Six to twelve year: The total number of cases was 244 . In this age group, most commonly referred cases for EEG was seizure disorder $(n=198,81.14 \%)$. Other cases included meningitis/encephalitis ( $n=17,6.96 \%)$, and febrile seizure ( $n=12,4.91 \%$ ) (Table 3).

Details of provisional clinical and electrophysiological diagnoses of pediatric patients referred for EEG during 2006 to 2009 at BPKIHS

From the 623 cases, EEG recording was found to be abnormal in 352 cases and normal in 271 cases (Table 4).

Seizure disorder and EEG: From the total 623 cases, 370 (59\%) cases were clinically diagnosed as seizure disorder. In the EEG, from these 370 cases, 239 (64.59\%) were consistent with clinical diagnosis and the remaining 131 (35.40\%) were normal with no epileptiform discharges (Table 4).

Birth asphyxia with hypoxia-induced encephalopathy (BA with HIE) and EEG: From the 623 cases, 66 (10.59\%) cases were BA with HIE. From the 66 cases, 33 (50\%) EEG recordings showed epileptiform discharges and remaining 33 (50\%) were normal (Table 4).

Atypical febrile seizure and EEG: From the total cases of 623 , the cases of atypical febrile seizure were 94 cases (15.08\%). From the 94 cases, only 27 (28.72\%) EEG recordings showed epileptiform discharges and remaining

Table 3. Relative frequency of cases of EEG done during 2006 to 2009 at BPKIHS.

\begin{tabular}{|c|c|c|c|c|}
\hline \multirow{2}{*}{ Cases } & \multicolumn{3}{|c|}{ Age group (years) } & \multirow[b]{2}{*}{$\begin{array}{l}\text { Total } \\
(n=623)\end{array}$} \\
\hline & $\begin{array}{c}<1 \\
(n=142)\end{array}$ & $\begin{array}{c}1-5 \\
(n=237)\end{array}$ & $\begin{array}{c}6-12 \\
(n=244)\end{array}$ & \\
\hline Seizure disorder & $36(25.35 \%)$ & $136(57.38 \%)$ & 198(81.14\%) & $370(59.39 \%)$ \\
\hline $\begin{array}{l}\text { Birth asphyxia with hypoxic-induced en- } \\
\text { cephalopathy }\end{array}$ & $68(47.88 \%)$ & - & - & $68(10.91 \%)$ \\
\hline Seizure disorder with co-morbidity & $4(2.81 \%)$ & $9(3.79 \%)$ & $3(1.22 \%)$ & $16(2.56 \%)$ \\
\hline Febrile seizure & $9(6.33 \%)$ & $73(30.80 \%)$ & $12(4.91 \%)$ & $94(15.08 \%)$ \\
\hline Meningitis/encephalitis & $11(7.74 \%)$ & $11(4.64 \%)$ & $17(6.96 \%)$ & $39(6.26 \%)$ \\
\hline Cerebral palsy & $5(3.52 \%)$ & $5(2.10 \%)$ & - & $10(1.60 \%)$ \\
\hline Miscellaneous & $9(6.33 \%)$ & $3(1.26 \%)$ & $14(5.73 \%)$ & $26(4.17 \%)$ \\
\hline
\end{tabular}

Less than one year: The total number of cases was 142 . The most frequent cases was birth asphyxia with hypoxicinduced encephalopathy ( $n=68,47.88 \%$ ) followed by seizure disorder ( $n=36,25.35 \%)$. Likewise, other cases were meningitis/encephalitis ( $n=11,7.74 \%)$, febrile seizure $(n=9$, $6.33 \%$ ), cerebral palsy ( $n=$ five, $3.52 \%$ ) and seizure disorder with co-morbidity ( $n=4,2.81 \%$ ) (Table 3$)$.

One to five year: The total number of cases was 237. Seizure disorder ( $n=136,57.38 \%$ ) was the major cases referred for EEG, followed by atypical febrile seizure ( $n=73,30.80 \%)$. Besides these cases, there were meningitis/encephalitis
67 (71.27\%) were normal (Table 4).

Meningitis/Encephalitis and EEG: From the 623 cases, meningitis/encephalitis was 39 (6.26\%) cases. From these 39 cases, 20 (51.28\%) EEG recordings were with epileptiform discharges and 19 (48.71\%) were normal (Table 4).

Seizure disorder with co-morbidity and EEG: From the 623 cases, 16 (2.56\%) referral cases were seizure disorder with co-morbidity. From these 16 cases, 11 (68.75\%) EEG recording showed epileptiform activities and remaining five $(31.25 \%)$ showed normal EEG (Table 4). 
Table 4. Co-tabulation of provisional clinical diagnoses and electro-diagnosis of patients referred for EEG during 2006 to 2009 at BPKIHS.

\begin{tabular}{|c|c|c|c|c|}
\hline \multirow{2}{*}{$\begin{array}{c}\text { Provisional Clinical } \\
\text { diagnoses }\end{array}$} & \multicolumn{2}{|c|}{ No. of patients } & \multicolumn{2}{|c|}{ Electro-diagnosis (EEG) } \\
\hline & $\begin{array}{l}\text { Enrolled } \\
(n=634)\end{array}$ & $\begin{array}{l}\text { Included } \\
(n=623)\end{array}$ & $\begin{array}{c}\text { Abnormal } \\
(n=352,56.50 \%)(\%)\end{array}$ & $\begin{array}{c}\text { Normal } \\
(n=271, \\
43.49 \%)(\%)\end{array}$ \\
\hline Seizure disorder & 372 & $370(59 \%)$ & $239(64.59 \%)$ & $131(35.40 \%)$ \\
\hline Seizure disorder with co-morbidity & 17 & $16(2.56 \%)$ & $11(68.75 \%)$ & $5(31.25 \%)$ \\
\hline Febrile seizure & 94 & $94(15.08 \%)$ & $27(28.72 \%)$ & $67(71.27 \%)$ \\
\hline Meningitis/encephalitis & 42 & $39(6.26 \%)$ & $20(51.28 \%)$ & $19(48.71 \%)$ \\
\hline BA with HIE* & 69 & $66(10.59 \%)$ & $33(50.0 \%)$ & $33(50.0 \%)$ \\
\hline Cerebral palsy & 11 & $10(1.60 \%)$ & $9(90.0 \%)$ & $1(10.0 \%)$ \\
\hline Miscellaneous & 29 & $28(4.49 \%)$ & $13(46.42 \%)$ & $15(53.57 \%)$ \\
\hline
\end{tabular}

Table 5. Relationship between provisional clinical diagnosis and electroencephalographic diagnosis of patients referred for EEG during 2006 to 2009 at BPKIHS

\begin{tabular}{|c|c|c|c|c|c|c|c|}
\hline \multirow[t]{2}{*}{ Diagnoses } & \multirow{2}{*}{$\begin{array}{l}\text { Cate- } \\
\text { gory }\end{array}$} & \multicolumn{2}{|c|}{ EEG } & \multirow{2}{*}{$\begin{array}{l}p \text { - } \\
\text { value }\end{array}$} & \multirow{2}{*}{$\begin{array}{l}\text { Odds } \\
\text { Ratio }\end{array}$} & \multicolumn{2}{|c|}{$\begin{array}{c}\text { Odds Ratio } \\
95 \% \mathrm{Cl}\end{array}$} \\
\hline & & $\begin{array}{l}\text { Ab- } \\
\text { nor- } \\
\text { mal }\end{array}$ & $\begin{array}{l}\text { Nor- } \\
\text { mal }\end{array}$ & & & Lower & Upper \\
\hline $\begin{array}{l}\text { Seizure } \\
\text { disorder }\end{array}$ & $\begin{array}{l}\text { Yes } \\
\text { No }\end{array}$ & $\begin{array}{l}239 \\
113\end{array}$ & $\begin{array}{l}131 \\
140\end{array}$ & 0.001 & 2.26 & 1.61 & 3.18 \\
\hline $\begin{array}{l}\text { Seizure } \\
\text { disorder } \\
\text { with co- } \\
\text { morbidity }\end{array}$ & $\begin{array}{l}\text { Yes } \\
\text { No }\end{array}$ & $\begin{array}{l}11 \\
341\end{array}$ & $\begin{array}{l}5 \\
266\end{array}$ & 0.316 & 1.72 & 0.54 & 5.74 \\
\hline $\begin{array}{l}\text { Febrile } \\
\text { seizure }\end{array}$ & $\begin{array}{l}\text { Yes } \\
\text { No }\end{array}$ & $\begin{array}{l}27 \\
325\end{array}$ & $\begin{array}{l}67 \\
204\end{array}$ & 0.001 & 0.25 & 0.15 & 0.42 \\
\hline $\begin{array}{l}\text { Menin- } \\
\text { gitis/en- } \\
\text { cephalitis }\end{array}$ & $\begin{array}{l}\text { Yes } \\
\text { No }\end{array}$ & $\begin{array}{l}20 \\
332\end{array}$ & $\begin{array}{l}19 \\
252\end{array}$ & 0.497 & 0.8 & 0.40 & 1.60 \\
\hline $\begin{array}{l}\text { BA with } \\
\text { HIE* }^{*}\end{array}$ & $\begin{array}{l}\text { Yes } \\
\text { NO }\end{array}$ & $\begin{array}{l}33 \\
319\end{array}$ & $\begin{array}{l}33 \\
238\end{array}$ & 0.259 & 0.75 & 0.43 & 1.28 \\
\hline $\begin{array}{l}\text { Cerebral } \\
\text { palsy }\end{array}$ & $\begin{array}{l}\text { Yes } \\
\text { No }\end{array}$ & $\begin{array}{l}9 \\
353\end{array}$ & $\begin{array}{l}1 \\
270\end{array}$ & 0.049 & 6.88 & 0.89 & 145.95 \\
\hline $\begin{array}{l}\text { Miscella- } \\
\text { neous }\end{array}$ & Yes & $\begin{array}{l}13 \\
339\end{array}$ & $\begin{array}{l}15 \\
256\end{array}$ & 0.271 & 0.65 & 0.29 & 1.48 \\
\hline
\end{tabular}

*BA with HIE= birth asphyxia with hypoxic-induced encephalopathy

Cerebral palsy and EEG: From the 623 cases, 10 (1.60\%) cases referred for EEG were cerebral palsy. From these 10 cases, nine (90\%) EEG recordings showed epileptiform discharges and only one (10.0\%) showed normal EEG (Table 4).

Relationship between provisional clinical diagnoses and electroencephalographic diagnoses of pediatric patients referred for EEG during 2006 to 2009 at BPKIHS

The odd ratio was 2.26 (95 percent $\mathrm{Cl}=1.61$ to 3.18 ) in seizure disorder and 6.88 (95 percent $\mathrm{Cl}=0.89$ to 145.95 ) in cerebral palsy in which detection of epileptiform discharges by EEG in both the cases was significantly high (seizure disorder, $p=0.001$ and cerebral palsy, $p=0.049)$. However, in febrile seizure the odd ratio was 0.25 (95 percent $\mathrm{Cl}=0.15$ to 0.42$)$ in which EEG detected significantly less $(p=0.001)$ epileptiform activities (Table 5).
According to the age groups, in one to five years, odd ratio was 10.04 (95 percent $\mathrm{Cl}=1.25$ to 217.46) in seizure disorder with co-morbidity in which EEG detected significantly high epileptiform discharges $(p=0.012)$. There was a significant relationship between cerebral palsy and EEG $(p=0.019)$. The odd ratio was 0.35 (95 percent $\mathrm{Cl}=0.18$ to 0.66 ) in febrile seizure in which the EEG diagnosis was highly negative ( $p=$ 0.001) (Table 6).

In six to twelve years, the odd ratio was 2.94 (95 percent $\mathrm{Cl}=$ 1.43 to 6.06 ) in seizure disorder in which EEG significantly detected epileptiform discharges $(p=0.001)$. The odd ratio was 0.16 (95 percent $\mathrm{Cl}=0.04$ to 0.63 ) in febrile seizure in which the EEG diagnosis was significantly negative ( $p=$ 0.003) (Table 6).

\section{DISCUSSION}

The reports on EEG done of patients in whom EEG is indicated are rare in Nepal. We attempted to document the demographic profiles, relative frequency of disorders/ diseases and clinico-electrodiagnostic relationship of 623 pediatric patients referred for EEG during 2006 to 2009 at BPKIHS. Further, we aimed to analyze the relationship between provisional clinical and electrophysiological diagnoses.

In our study, we enrolled the EEG reports of children from neonate up to 12 years of age as through late pre-school and into adolescence the characteristic features of the adult EEG emerge. ${ }^{4}$ During the three-year study period, the number of male children undergoing EEG was almost three times more than that of female. Seizure disorder was one of most common indications for doing EEG. This is in alignment with published report that the seizures are common in male. ${ }^{5,6}$ In male, most common age group was between one to five years followed by six to 12 years. There is report saying that seizures have peak frequency of age at onset in two to five years which is similar to our study. ${ }^{5}$ However, the study did not differentiate the age group on sex basis. We found that the trend was opposite in female i.e. 6 to 12 years followed by one to five years. 
Table 6. Relationship between provisional clinical diagnoses and electroencephalographic diagnoses of patients in terms of age group referred for EEG during 2006 to 2009 at BPKIHS.

\begin{tabular}{|c|c|c|c|c|c|c|c|c|}
\hline \multirow{2}{*}{$\begin{array}{l}\text { Age group } \\
\text { (years) }\end{array}$} & \multirow[t]{2}{*}{ Diagnosis } & \multirow[t]{2}{*}{ Category } & \multicolumn{2}{|c|}{ EEG } & \multirow[t]{2}{*}{ p-value } & \multirow[t]{2}{*}{ Odds Ratio } & \multicolumn{2}{|c|}{ Odds Ratio 95\% Cl } \\
\hline & & & abnormal & normal & & & lower & upper \\
\hline \multirow[t]{14}{*}{$<1$} & Seizure disorder & Yes & 17 & 19 & 0.755 & 1.13 & 0.49 & 2.58 \\
\hline & & No & 46 & 58 & & & & \\
\hline & Seizure disorder with & Yes & 1 & 3 & 0.627 & 0.40 & 0.02 & 4.45 \\
\hline & co-morbidity & No & 62 & 74 & & & & \\
\hline & BA with $\mathrm{HIE}^{*}$ & Yes & 33 & 33 & 0.261 & 1.47 & 0.71 & 3.03 \\
\hline & & No & 30 & 34 & & & & \\
\hline & Febrile seizure & Yes & 2 & 7 & 0.185 & 0.33 & 0.05 & 1.82 \\
\hline & & No & 61 & 70 & & & & \\
\hline & Meningitis/encephalitis & Yes & 4 & 7 & 0.754 & 0.68 & 0.16 & 2.75 \\
\hline & & No & 59 & 70 & & & & \\
\hline & Cerebral palsy & Yes & 4 & 1 & 0.174 & 5.15 & 0.52 & 124.35 \\
\hline & & No & 59 & 76 & & & & \\
\hline & Miscellaneous & Yes & 2 & 7 & 0.185 & 0.33 & 0.05 & 1.82 \\
\hline & & No & 61 & 70 & & & & \\
\hline \multirow[t]{12}{*}{$1-5$} & Seizure disorder & Yes & 68 & 68 & 0.156 & 1.45 & 0.84 & 2.52 \\
\hline & & No & 42 & 61 & & & & \\
\hline & Febrile seizure & Yes & 21 & 52 & 0.001 & 0.35 & 0.18 & 0.66 \\
\hline & & No & 89 & 77 & & & & \\
\hline & Seizure disorder with & Yes & 8 & 1 & 0.012 & 10.04 & 1.25 & 217.46 \\
\hline & co-morbidity & No & 102 & 128 & & & & \\
\hline & Meningitis/encephalitis & Yes & 6 & 5 & 0.561 & 1.43 & 0.37 & 5.59 \\
\hline & & No & 104 & 124 & & & & \\
\hline & Cerebral palsy & Yes & 5 & 0 & 0.019 & & & \\
\hline & & No & 105 & 129 & & & & \\
\hline & Miscellaneous & Yes & 2 & 3 & 1.0 & 0.78 & 0.09 & 5.84 \\
\hline & & No & 108 & 126 & & & & \\
\hline \multirow[t]{10}{*}{$6-12$} & Seizure disorder & Yes & 154 & 44 & 0.001 & 2.94 & 1.43 & 6.06 \\
\hline & & No & 25 & 21 & & & & \\
\hline & Febrile seizure & Yes & 4 & 8 & 0.003 & 0.16 & 0.04 & 0.63 \\
\hline & & No & 175 & 57 & & & & \\
\hline & Seizure disorder with & Yes & 2 & 1 & 1.0 & 0.72 & 0.05 & 20.50 \\
\hline & co-morbidity & No & 177 & 64 & & & & \\
\hline & Meningitis/encephalitis & Yes & 10 & 7 & 0.159 & 0.49 & 0.16 & 1.51 \\
\hline & & No & 169 & 58 & & & & \\
\hline & Miscellaneous & Yes & 9 & 5 & 0.428 & 0.64 & 0.18 & 2.28 \\
\hline & & No & 170 & 60 & & & & \\
\hline
\end{tabular}

In a box of contingency table had $<5$ cases then, Fisher Exact $p$ values were taken.

*BA with $\mathrm{HIE}=$ birth asphyxia with hypoxic-induced encephalopathy

Most of the patients referred for EEG were from the eastern part of Nepal simply because institute lies there. Most frequently, patients referred were from Sunsari district, followed by Morang and Jhapa districts respectively compared to other districts. It is probably be due to their proximity, accessibility and feasibility to BPKIHS. In addition, EEG services started since the establishment of BPKIHS. Nowadays, this service has been started in few neighboring towns outside BPKIHS.

Seizure disorder (59.39\%) was the most common referral cases for EEG, followed by febrile seizure (15.08\%) and birth asphyxia with hypoxic-induced encephalopathy (10.91\%). Others were meningitis/encephalitis (6.26\%), seizure disorder with co-morbidity $(2.56 \%)$ and cerebral palsy
(1.60\%). According to the age, in seizure disorder, most common age-group referred for EEG was six to twelve years (81.14\%), followed by one to five years (38\%). This finding in seizure disorder is vague. The referred cases of seizure disorder were not classified. Because brain growth and neurophysiological maturation are incomplete in children, epileptic seizures and epilepsy pose specific problems, as symptomatology is often dependent on age. ${ }^{4}$ Likewise, in febrile seizure more referral group was one to five years (30.8\%) which is most common seizure disorder in children younger than five years of age, followed by six to twelve years (4.91\%). ${ }^{7}$ The referral frequency for EEG in infections of nervous system (meningitis/encephalitis) was almost similar among the age groups (six to twelve years: $6.96 \%$; 
less than one year: $7.74 \%$ and one to five year: $4.64 \%)$. In cerebral palsy, the referred age group was less than one year $(3.52 \%)$ and one to five years $(2.10 \%)$.

From the total 623 cases involved in our study, the total EEG recording was abnormal in $56.50 \%$ and normal in 43.49 $\%$ cases (Table 4$)$. In seizure disorder, EEG recording was abnormal in $64.59 \%$ and normal in $35.40 \%$ cases (Table 4). EEG showed significant epileptiform activities in seizure disorder (Table 5) and according to age group specifically in six to 12 years (Table 6). In seizure disorder with comorbidity, EEG recording was abnormal in $68.75 \%$ and normal in $31.25 \%$ (Table 4). The EEG was highly positive (Table 6) in it specifically in one to five years.

Published figures for diagnostic sensitivity of EEG range between 25 to $55 \%, 29$ to $38 \%$. ${ }^{8,9}$ On first EEG recording, some reports show that EEGs identify 29 to 55 percent of seizures, 10 other reports show only $56 \% .^{10,11}$ Even with expert clinical evaluation and repeated recordings, the sensitivity of EEG is $70 \%$, with a specificity of $78 \%$, or 80 to $90 \%$, or 69 to $77 \% .^{9-11}$ On a first standard EEG recording, around $40 \%$ of children with seizures will have a normal record or up to about half of patients with epileptic disorders may have one normal inter-ictal EEG. 8,9,12 Around $10 \%$ of patients or from 10 to $40 \%$ with epilepsy never show epileptiform discharges. ${ }^{9,10}$ Hence, a normal or negative EEG cannot be used to rule out the clinical diagnosis of an epileptic seizure. In our case, we found $64.59 \%$ of seizure disorder and $68.75 \%$ of seizure disorder with co-morbidity with abnormal EEG recording which is higher than the previous reported data. It could be because highly selected cases were referred for EEG as our hospital is a referral center. Additionally, our data include follow-up EEG recordings as well.

Early EEG is a reliable predictor of outcome in hypoxic induced encephalopathy. A normal or mildly abnormal EEG results within six hours after birth were associated with normal neurodevelopmental outcomes at two years. ${ }^{13}$ An abnormal EEG pattern of suppression-burst or continuous low voltage within three to eight hours of life was associated with a poor outcome, whereas a normal EEG almost invariably indicated a good outcome in term infants. ${ }^{14}$ The additional benefit of continuous EEG monitoring would be the ability to detect electrographic seizures. ${ }^{15}$ The presence of electrographic seizures was correlated associated with a higher rate of abnormal neurodevelopmental outcomes. ${ }^{13}$ Whether this is a reflection of underlying injury and whether seizures cause additional damage remains unclear. ${ }^{16,17}$ However, we don't have an advance laboratory set up in NICU to record EEG immediately after birth. We recorded EEG of referral cases of neonates diagnosed with birth asphyxia with hypoxic-induced encephalopathy ( $n=66)$ who were less than one month in which $50 \%$ had abnormal and $50 \%$ had normal EEG. There is a scope to trace them and record EEG who had previous abnormal EEG to see their developmental outcome.
In febrile seizure ( $n=94$ ), EEG recording was abnormal in $28.72 \%$ cases and normal in $71.27 \%$ cases (Table 4 ). Overall, EEG detected significantly less epileptiform activities in febrile seizure (Table 5). It was most common in one to five years and the EEG diagnosis was significantly negative in this age group. Studies have shown that the yield of routine EEG is low in neurologically normal children with febrile seizures even if the seizure is complex. ${ }^{18}$ One study showed that overall, $6.5 \%$ had febrile seizures (including complex) from 438 consecutive pediatric EEGs over a one-year period and none had epileptiform discharges. ${ }^{19}$ Other showed that $15 \%$ of all EEGs recorded for febrile seizures and only $4.85 \%$ were abnormal with background rather than epileptiform abnormalities. ${ }^{20}$ Therefore, there suggestions that the routine practice of obtaining EEG in neurologically normal children with febrile seizures is not justified..$^{21}$ Our findings are supported by these reports though abnormal EEG was more in our study than in these studies.

In meningitis/encephalitis ( $n=39)$, EEG was abnormal in $51.28 \%$ cases and normal in $48.71 \%$. Abnormal EEG in meningitis has also been reported in $50 \%$ by Kumar et.al; $33.33 \%$ by Rose et.al ; and $17 \%$ by Mizrahi et.al. ${ }^{22-24}$ Regarding encephalitis, EEG is of value particularly in patients with herpes simplex type 1 encephalitis. ${ }^{25,26}$ These reports are similar to our study results.

In cerebral palsy $(n=10)$, EEG were abnormal in $90 \%$ cases and normal in $10 \%$ case (Table 3). EEG showed significant epileptiform activities in cerebral palsy (Table 5). In one to five years, the EEG was highly positive (Table 6). There are similar findings in other studies too. The incidence of EEG abnormalities is high (spastic tetraplegia and spastic diplegia: epilepsy in $60 \%$, EEG abnormalities in 80\%). There is relatively high incidence (44\%) of epileptiform discharges even in children without clinical evidence of seizures peaking between the ages of four and six years. ${ }^{27}$ Similarly, there are studies showing that tetraplegic cerebral palsy had a higher incidence of epilepsy (60.5\%). EEG was confirmed abnormal in epileptic cerebral palsy as $90.3 \%$, and in non-epileptic cerebral palsy as $39.5 \%$. Focal epileptiform activity, generalized slowing, and multifocal epileptiform activity were significantly frequent in epileptic cerebral palsy. ${ }^{28}$

Since it is a retrospective study, we have depended only on requisite form for the information of the patients. In future, we can design cross-sectional or longitudinal types of study, collaborate with the concern referral departments and can correlate the sign and symptoms of specific seizure disorder or other neurological disorders/diseases, family history/history of patients with EEG features, timing of the EEG recording and their follow-up.

\section{CONCLUSION}

Male children had preponderance over female. Most common age group that underwent EEG was one to five 
and 6 to 12 years whereas female had opposite trend. Predominant cases for EEG were seizure disorder, followed by febrile seizure and birth asphyxia with hypoxic-induced encephalopathy respectively. Abnormal EEG activity was highly associated with seizure disorder and cerebral palsy but was not associated with febrile seizure.

Strength of the study: The study is first of its kind since published data on reports of EEG done of Nepalese pediatric patients with sample size like ours is almost absent. It has provided preliminary demographic profile, pattern and frequency of neurological disorders/diseases with relationship between provisional clinical diagnoses and electrophysiological diagnoses (EEG) of children referred for EEG of eastern Nepal. The data of our study builds a background and can be used for the future research in the related field.

\section{REFERENCES}

1. Aminoff MJ. Electroencephalography: General Principals and clinical applications. In: Aminoff MJ. Electrodiagnosis in clinical neurology. 4th ed. Philadelphia: Churchill Livingstone; 1999. p.37-80.

2. Smith S J. EEG in the diagnosis, classification, and management of patients with epilepsy. J Neurol Neurosurg Psychiatry 2005 Jun;76 (Suppl 2:ii)2-7.

3. Hahn JS and Tharp BR. Neonatal and pediatric electroencephalography. In: Aminoff M.J. Electrodiagnosis in clinical neurology. 4th ed. Philadelphia: Churchill Livingstone; 1999. p.81-127.

4. Colin D Binnie. General characteristics of EEG. In: Ronit M Pressler, Colin D Binnie, Raymond Cooper, Richard Robinson, editors. Neonatal and Paediatric Clinical Neurophysiology. Amsterdam, The Netherlands: Churchill Livingstone Elsevier; 2007. p. 230-23.

5. Shakya KN, Shrestha R, Baral MR. Epilepsy in children: an epidemiological study at Kathmandu Medical College Teaching Hospital Kathmandu. Kathmandu Uni Med J 2003 Jan-Mar; 1(1):1419.

6. Shah GS, Singh MK, Budhathoki S, Kalakheti BK, Baral DD. Clinicobiochemical profile of neonatal seizure. J Nepal Paediatr Soc 2008; 28(1):7-9.

7. Al-Khathlan Norah A, Jan Mohammed M. Clinical profile of admitted children with febrile seizures. Neurosciences 2005; 10 (1): 30-33.

8. Binnie CD. Epilepsy in adults: diagnostic EEG investigation. In: Kimura J, Shibasaki H, editors. Recent Advances in Clinical Neurophysiology. Amsterdam: Elsevier; 1996. p.217-22.

9. King MA, Newton MR, Jackson GD, Fitt GJ, Mitchell LA, Silvapull $\mathrm{MJ}$, et al. Epileptology of the first seizure presentation: a clinical, electroencephalographic and magnetic resonance imaging study of 300 consecutive patients. Lancet 1998 Sept; 352: 1007-11.

10. Pillai J and Sperling MR. Interictal EEG and the diagnosis of epilepsy. Epilepsia 2006; 47 (suppl 1): 14-22.

11. Stroink H, van Donselaar CA, Geerts AT, Peters AC, Brouwer OF, Arts WF. The accuracy of the diagnosis of paroxysmal events in children. Neurology 2003 Mar; 60(6): 979-82.

12. Carpay JA, de Weerd AW, Schimsheimer RJ, Stroink H, Brouwer OF, Peters AC, et al. The diagnostic yield of a second EEG after partial sleep deprivation: a prospective study in children with newly diagnosed seizures. Epilepsia 1997; 38(5):595-99.

13. Murray DM, Boylan GB, Ryan CA and Connolly S. Early EEG Findings in Hypoxic-Ischemic Encephalopathy Predict Outcomes at 2 Years. Pediatrics 2009 Sept; 124(3): e459-67.

14. Ong L C, Kanaheswari Y, Chandran V, Rohana J, Yong S C, Boo N Y. The usefulness of early ultrasonography, electroencephalography and clinical parameters in predicting adverse outcomes in asphyxiated term infants. Singapore Med J 2009; 50(7): 705-9.

15. Murray DM, Boylan GB, Ali I, Ryan CA, Murphy BP, Connolly S. Defining the gap between electrographic seizure burden, clinical expression and staff recognition of neonatal seizures. Arch DisChild Fetal Neonatal Ed 2008 May; 93(3): F187-91.

16. Wirrell EC, Armstrong EA, Osman LD, Yager JY. Prolonged seizures exacerbate perinatal hypoxic ischemic brain damage. Pediatr Res 2001 Oct; 50(4):445- 54

17. Yager JY, Armstrong EA, Mujashita H, Wirrel EC. Prolonged neonatal seizures exacerbate hypoxicischemic brain damage: correlation with cerebral energy metabolism and excitatory amino acid release. Dev Neurosci 2002; 24(5): 367-81.

18. Maytal J, Steele R, Eviatar L, Novak G. The value of early postictal EEG in children with complex febrile seizures. Epilepsia 2000 Feb; 41(2): 219-21.

19. Jan MM. Assessment of the Utility of Pediatric Electroencephalography. Seizure 2002 Mar; 11(2): 99-103.

20. Udani V. Paediatric epilepsy- an Indian perspective. Indian J Paediatr 2005 Apr; 2 (4): 309-13.

21. Mohammed M. Jan, John P. Girvin. Febrile seizures update and controversies. Neurosciences 2004; 9(4): 235-42.

22. Kumar A, Gupta A, Talukdar B. Clinico-etiological and EEG profile of neonatal seizure. Indian J of Paediatr 2007 Jan;74(1):33-7.

23. Rose AL, Lombroso CT. Neonatal seizure status: A study of clinical, pathological and electroencephalographic features in 137 full term babies with long term follow up. Paediatrics 1970 Mar; 45(3):404-25.

24. Mizrahi EM, Kellaway P. Characterization and classification of neonatal seizures. Neurology 1987 Dec; 37(12):1837-44.

25. Whitley RJ. Viral encephalitis. N Engl J Med 1990 Jul; 323(4):242-50.

26. Whitley RJ, Gnann JW. Viral encephalitis: familiar infections and emerging pathogens. Lancet 2002 Feb; 359(9305):507-13.

27. Pressler RM. Neurophysiology in paediatrics. In: Ronit M Pressler, Colin D Binnie, Raymond Cooper, Richard Robinson, editors. Neonatal and Paediatric Clinical Neurophysiology. Amsterdam, The Netherlands: Churchill Livingstone Elsevier; 2007. p. 321-22.

28. Senbil N, Sonel B, Aydin OF, Gu"rer YK. Epileptic and non-epileptic cerebral palsy: EEG and cranial imaging findings. Brain Dev 2002 Apr; 24 (3) 166-69. 